\title{
La toma de decisiones y CRISPR: ¿Quién es dueño de mis genes?
}

\author{
Decision making and CRISPR: Who owns my genes?
}

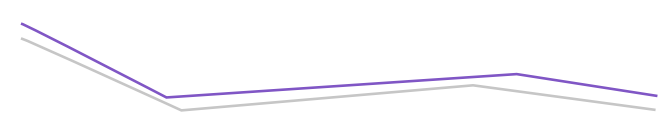

Marcelino Montiel-Herrera*®

Montiel-Herrera, M. (2018). La toma de decisiones y CRISPR: ¿Quién es dueño de mis genes? Investigación y Ciencia de la Universidad Autónoma de Aguascalientes, 26(75), 81-84.

RESUMEN

La toma de decisiones voluntarias es derivada de la actividad de los circuitos neuronales corticales. Una persona sana es capaz de tomar sus propias decisiones, incluso cuando desea modificar su cuerpo. La biotecnología CRISPR/Cas9 brinda el potencial de editar el genoma de células eucariotas y procariotas, abriendo la oportunidad de que cada individuo modifique su propio genoma, basado en su propia decisión. Sin embargo, este tema es altamente controversial a pesar de la evidencia científica que muestra los beneficios potenciales de CRISPR/Cas9 para el tratamiento de algunas enfermedades y para el desarrollo de alternativas biotecnológicas. Esta nota expone de manera básica cómo funciona CRISPR/Cas9 y aborda algunas implicaciones que tiene la toma de decisiones sobre el manejo de CRISPR/Cas9 para editar las células humanas.

\section{ABSTRACT}

Decision making derives from the activity of cortical neurons in the brain. A healthy person is able to make its own decisions -on a daily basis- even when these involve changing its body. CRISPR/Cas9

Palabras clave: CRISPR/Cas9; edición de genes; toma de decisiones; bioética.

Keywords: CRISPR/Cas9; gene editing; decision making; bioethics.

\section{Recibido: 9 de marzo de 2018, aceptado: 1 de agosto de 2018}

* Departamento de Medicina y Ciencias de la Salud, Universidad de Sonora. Blvd. Luis Donaldo Colosio y Reforma, Colonia Centro S/N, C. P. 83000, Hermosillo, Sonora, México. Correo electrónico: marcelino. montiel@unison.mx

$凶$

Autor para correspondencia biotechnology gives the opportunity to edit the genome of eukaryote and prokaryote cells, opening the possibility to every individual to modify its own genome based on its own decision. However, this theme is highly controversial yet all the scientific information available that suggest the potential benefits of CRISPR/Cas9 to treat diseases and to develop new alternatives for the bio-industries. This news approaches some features of the topic decision making upon CRISPR/Cas9 technology as intended to edit human cells and explains the basic concepts of this outstanding-edge molecular technique.

\section{INTRODUCCIÓN}

Es común asumir que una persona sana es cabalmente responsable de sus acciones y que puede decidir qué sí y qué no hacer con su cuerpo. Por ejemplo, un individuo puede optar por modificar a través de procedimientos quirúrgicos estéticos la estructura de su cara o las dimensiones físicas de sus glúteos y pechos sin pedir autorización a una institución reguladora. Incluso en algunas culturas hay tradiciones en donde los individuos modifican sus cuerpos a través de procedimientos convencionales para representar adecuadamente a su clan [e.g., las Padaungs, conocidas como mujeres cuello de jirafa; la tribu Mursi, quienes colocan platos de arcilla en su labio inferior, como se puede ver en Khammuang (1998) y en Turton (2004)], otra vez, sin instituciones que los restrinjan. Sin embargo, cuando se trata de modificar los genes de un individuo, el tema se torna sumamente controversial y en esencia, la ética y lo incierto se adueñan de la situación. ¿̇Es uno dueño de sus genes? Si los genes están en las células del cuerpo, ¿̇entonces cada individuo podría decidir qué hacer con sus genes? 
Desde un punto de vista neurobiológico, la toma de una decisión es procesada por el cerebro y si esta se ejecuta, es representada en una conducta específica (e.g. halar una palanca). No obstante, el procesamiento de la información perceptual en el cerebro que potencialmente puede generar una conducta puede ser alterada o modificada experimentalmente, o bien, por factores ajenos a la fisiología cerebral normal de un individuo (Romo, Lemus, \& de Lafuente, 2012). Por ejemplo, en algunos países (e.g., Reino Unido y EE. UU.) delincuentes acusados de conductas criminales (e.g., asesinato, pedofilia) han sido defendidos ante la corte basando el alegato de defensa en que los acusados presentaban patologías en el cerebro (e.g., tumor en la corteza cerebral) y que estas podrían haber influenciado la actividad de los circuitos neuronales responsables de la toma de decisiones y que por ello los acusados no serían responsables completamente de su conducta criminal. Es decir, si se toma en cuenta que una patología, como el tumor, no debería de estar en el cerebro del acusado, podría plantearse si realmente es culpable de cometer el crimen o de señalar al tumor cerebral como el responsable de dicho suceso (Kelland, 29 de agosto de 2012). Ante el contexto antes descrito, ¿̇cómo podría decirse que uno es dueño y responsable de sus acciones?, ¿solamente aplicaría esto para las personas sanas?

Si una persona pudiera modificar sus genes de manera reversible (por su propia voluntad) para cambiarse una característica física, la toma de esa decisión de acuerdo con la neurociencia podría sugerir resultados controversiales dependiendo del estado neurofisiológico del individuo. Entonces, ¿quién podría decidir si uno es apto para modificar sus genes?, ¿debería esto regularse? Aún no es claro esto, pero la edad del sujeto sería un factor determinante para definirlo. La biotecnología contribuye de manera importante con esta fascinante interrogante o planteamiento ético que roza los umbrales de la investigación experimental en seres humanos y probablemente influya con mucha fuerza para la generación de respuestas.

En un lapso relativamente corto un grupo de investigadores de 12 países dilucidaron un mecanismo celular denominado CRISPR (Clustered Regularly Interspaced Short Palindromic Repeats; pronunciado CRISPER, que podría traducirse al español como secuencias de nucleótidos palindrómicas cortas, repetidas, agrupadas y regularmente espaciadas), el cual tiene el potencial de editar el genoma de céIulas procariotas y eucariotas. Dicho de manera simple, CRISPR brinda la oportunidad de insertar, elimi- nar o generar mutaciones en un gen de interés en el genoma de una célula (Lander, 2016). Por ejemplo, potencialmente se podría editar en una línea germinal animal o vegetal un gen defectuoso y reemplazarlo por uno funcional.

Actualmente CRISPR es una herramienta biotecnológica novedosa, eficiente, versátil y fácil de diseñar para manipular la secuencia de nucleótidos en un gen, ya sea para eliminarlo o modificarlo. En la base de datos PubMed de la Biblioteca Nacional de Medicina de EE. UU. (US National Library of Medicine, s. f.), CRISPR ha generado 8,766 trabajos publicados hasta febrero de 2018 (figura 1). CRISPR, cuyos descubridores, a consideración del autor del presente, deben ser galardonados con el Premio Nobel de Fisiología o Medicina en los años venideros, fue descrito por primera vez por el español Francisco Mojica, en sus trabajos entre 1993 y 2005, como un proceso celular de adaptación inmunológico utilizado por los microbios ante la invasión de virus para registrar y atacar las secuencias de nucleótidos virulentas y así otorgarles resistencia a estas (Lander, 2016), lo que puede consultarse en la línea de tiempo de CRISPR (Broad Institute, s. f.).

El mecanismo celular CRISPR Tipo II se puede consultar en Lander (2016), básicamente requiere de un arreglo (constructo) de CRISPR/Cas (CRISPR associated) compuesto por cuatro genes que codifican para las proteínas cas9, cas1, cas2 y cns2, y un pequeño RNA transactivador de CRISPR RNA (tracrRNA). Cas9 es una nucleasa (fosfodiesterasa) que confiere inmunidad al cortar el ADN virulento que

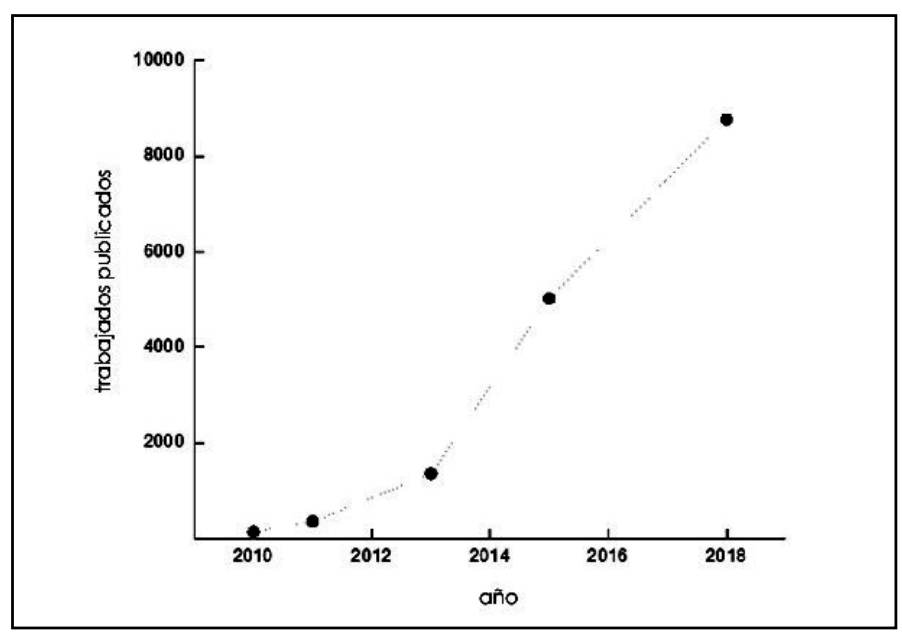

Figura 1. Tendencia del número de publicaciones científicas de CRISPR a través del tiempo. Antes de 2010, había publicados 85 artículos de CRISPR, los cuales incrementaron rápidamente a partir de ese año.

Elaboración propia. 


\section{IIVESTIGAGIÓn Y CUERCIA DE LA UกIVERSIDAD AUTÓOOOMA DE RGUASCHLIETTES}

83

empata con las secuencias espaciadoras, mientras que cas 1, cas 2 y cns2 agregan nuevas secuencias del ADN invasor. El constructo se transcribe y genera dos RNAs, un tracrRNA y una cadena larga de pre-CRISPR RNA (constituida por 61 nucleótidos: crRNA), los cuales hibridan y se procesan en secuencias cortas por las proteínas Cas9 y RNAsa III. El complejo resultante entre Cas9, tracrRNA y crRNA busca secuencias que complementen a las secuencias espaciadoras y en coordinación con un motivo adyacente protoespaciador (PAM: protospacer adjacent motif) se pueden hibridar. Una vez que Cas9 se une a la secuencia híbrida entre crRNA y la secuencia de ADN virulenta, hidroliza tres pares de bases río arriba del sitio de unión de PAM. Así, Cas9 al poseer dos dominios con actividad de endonucleasa (HNH y RuvC) los hidroliza y genera dos hebras sueltas con el potencial de unir nuevas secuencias de nucleótidos (Lander, 2016).

Por ejemplo, cuando una bacteria detecta la invasión de ADN virulento, produce dos secuencias de RNA cortas, una de ellas (secuencia guía de RNA) es complementaria a la secuencia del ADN viral. Estas dos hebras de RNA forman un complejo macromolecular con Cas9 (una nucleasa que puede hidrolizar los enlaces fosfodiéster en el ADN). Cuando la secuencia guía embona con la secuencia de ADN virulenta, Cas9 hidroliza la secuencia de ADN viral y elimina su virulencia. En este sentido, el diseño de secuencias guías de RNA específicas puede modificar puntualmente cualquier secuencia a la que empate, incluso dentro del núcleo de una célula de mamíferos. Para que esto suceda, el complejo CRISPR/Cas9 tiene que unirse a una secuencia adyacente (denominada PAM) a la secuencia de interés que uno quiere modificar, para que Cas9 pueda abrir (deshibridar) la secuencia de ADN y que la secuencia guía de RNA pueda hibridar con su cadena complementaria (secuencia de nucleótidos a modificar). Cuando eso sucede, la célula trata de corregir el corte del ADN (e.g., recombinación homóloga/no homóloga) pero este proceso de corrección genético es propenso a generar errores que conducen a la inactivación del gen, lo cual permite conocer la función específica de ese gen, o bien, se pueden editar secuencias específicas de un gen para reemplazar uno mutante (figura 2) (Lander, 2016).

Adicionalmente a CRISPR/Cas9 existen al menos dos herramientas biotecnológicas para la edición genómica, ZFN y TALEN, que han mostrado también ser eficientes, versátiles y fáciles de diseñar (Gaj, Gersbach, \& Barbas, 2013). En la actualidad estas herramientas biotecnológicas se han utilizado para generar resistencia a algunos virus, como el VIH, y

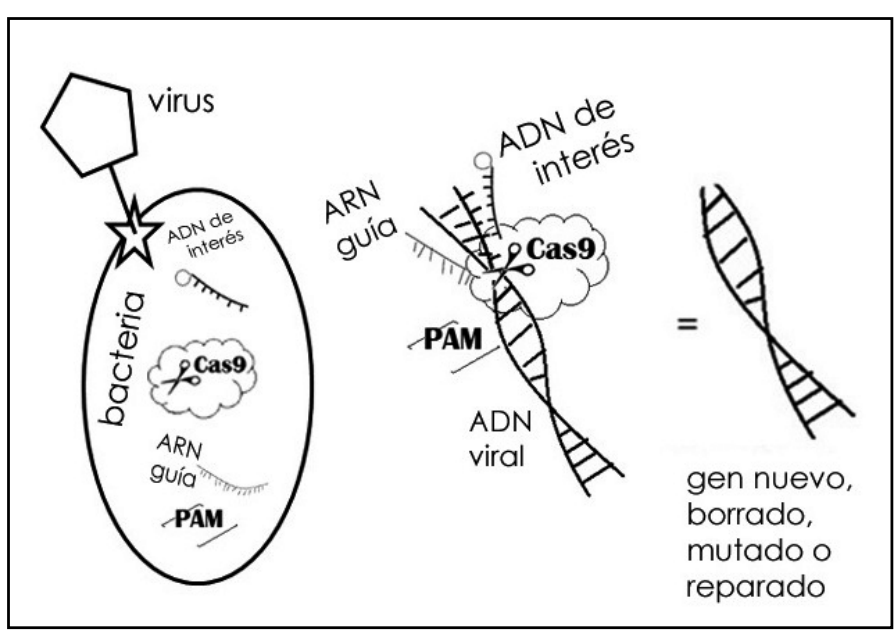

Figura 2. Representación del mecanismo de edición de un gen con CRISPR/Cas9.

Elaboración propia.

corregir mutaciones que generan aberraciones en genes, como los genes que producen la hemofilia $B$, la deficiencia de antitripsina $\alpha-1$ o las $\beta$-talasemias, entre otros (Gaj et al., 2013; Traxler et al., 2016; Xie et al., 2014).

No obstante, aunque estos tratamientos se han abordado experimentalmente en laboratorios, restan por explorarse todas las posibilidades que estas herramientas biotecnológicas de edición genómica (e.g., manipulación de genes, represión y activación transcripcional, alteraciones epigenéticas y screening funcionales, entre otras) pueden brindar para comprender y tratar problemáticas que atacan a los sistemas biológicos de interés ambiental, industrial y biomédico. Asimismo, brindan la alternativa de modificar sistemas vivos con el objetivo de explorar sus capacidades o incluso de crear nuevas funciones en ellos.

De acuerdo a la historia, todo nuevo desarrollo tecnológico puede utilizarse para hacer el bien - causar daño (e.g., eugenesia Nazi, armas mecánicas, armas biológicas, computadoras). CRISPR no está exento de esta suerte. Por ejemplo, el 3 de octubre de 2017, Josiah Zayner, un reconocido biohacker, tramismitió en vivo por la plataforma de Facebook una charla sobre las potenciales regulaciones que podrían tratar de imponer sobre el uso de la tecnología CRISPR y sobre el derecho que él tiene para decidir sobre sus genes. En el video Zayner compara el hallazgo de la creación de una computadora varias décadas atrás (que ahora una gran parte de la población mundial utiliza de manera personal) y plantea cómo dicha tecnología en su momento no tenía claramente el potencial 
IIVESTIGACIÓn Y CIERCIA DE LA UNIVERSIDAD AUTÓNOMA

84 DE RGUASCALIERTES que tenía por brindar y, más aún, que aún tiene por dar. En este sentido, él propone, así como Ellen Jorgensen de Genspace (organización sin lucro ubicada en Brooklyn, NY, USA), entre otros, que la regulación de CRISPR por organismos internacionales podría limitar y atrasar el desarrollo biotecnológico que puede brindar CRISPR (haciendo un símil con las computadoras) porque hoy día no se puede vislumbrar el potencial que CRISPR tiene, como en su momento lo tuvo la primera computadora. Más aún, en la transmisión que hizo Zayner se autodosificó "aparentemente" (entre comillas porque a través del video no se puede comprobar la veracidad de la dosis) un constructo de CRISPR para modificar su masa muscular (bíceps) argumentando que él es dueño de sus genes y que, por ende, él puede modificarlos si así lo decide. Como es de imaginarse, esto ha generado gran controversia y ha puesto sobre la mesa el debate sobre las regulaciones que debería tener CRISPR sobre la experimentación en humanos, como se ha prohibido en Bavaria, Alemania (Pearlman, 2017).

Sin embargo, agrupaciones civiles conformadas por científicos y ciudadanos, como los Stand-up
Labs, a los que se puede acceder desde DIY BIO (s. f.), distribuidos en más de 25 países (hasta la fecha no hay uno registrado en México), están a favor de que la biotecnología (como CRISPR) esté al alcance de todos, ya que cada ciudadano potencialmente podría generar nuevos desarrollos tecnológicos en los rubros de la electrónica, software, diseño de códigos, biología y química, entre otros, dependiendo de su entorno y sus problemáticas.

Varias décadas atrás, cuando se creó la primera computadora, era casi inimaginable el potencial tecnológico que esto podría representar para beneficio de la humanidad. En este mismo sentido, el poder biotecnológico que augura CRISPR para todos los campos del quehacer humano coloca el mismo panorama que brindó la computadora en sus inicios. Aun así, la regulación biotecnológica de CRISPR, o bien, el uso restringido de este procedimiento molecular (e.g., patentes, restricciones gubernamentales nacionales e internacionales) podrían poner en riesgo su potencial benéfico biotecnológico para el desarrollo de nuevas soluciones ante los problemas que atañen a nuestro ecosistema.

\section{REFERENCIAS}

- Broad Institute. (s. f.). CRISPR TIMELINE [Sitio de internet]. Recuperado de https://www.broadinstitute.org/what-broad/ areas-focus/project-spotlight/crispr-timeline

- DIY BIO. (s. f.). Local. [Base de datos]. Recuperada de https:// diybio.org/local/

- Gaj, T., Gersbach, C. A., \& Barbas, C. F. (2013). ZFN, TALEN and CRISPR/Cas-based methods for genome engineering. Trends in biotechnology, 31 (7), 397-405. doi.org/10.1016/j.tibtech.2013.04.004

- Kelland, K. (29 de agosto de 2012). Insight-Neuroscience in court: My brain made me do it. Health news [en línea]. Recuperado el 22 de noviembre de 2017, de https://www.reuters.com/ article/us-neuroscience-crime/insight-neuroscience-in-courtmy-brain-made-me-do-it-idUSBRE87S07020120829

- Khammuang, S. (1998). The phonological study of Padaung (Long-Necked Karen) at Ban Naisoi, Tambol Pang Mu, Muang District, Mae Hong Son Province (Tesis de maestría). Muang district, Mae Hong Son province, Thailand: Mahidol University. Recuperado de http://mulinet11.li.mahidol.ac.th/e-thesis/ scan/3636912.pdf

- Lander, E. S. (2016). The Heroes of CRISPR. Cell, 164(1-2), 18-28. doi.org/10.1016/j.cell.2015.12.041
Pearlman, A. (2017). My body, my genes. New Scientist, 22-23. doi: 10.1016/S0262-4079(17)32257-1

- Romo, R., Lemus, L., \& de Lafuente, V. (2012). Sense, memory, and decision-making in the somatosensory cortical network. Current Opinion in Neurobiology, 22 (6), 914-919. doi: 10.1016/j. conb.2012.08.002

- Traxler, E. A., Yao, Y., Wang, Y.-D., Woodard, K. J., Kurita, R., Nakamura, Y., ... Weiss, M. J. (2016). A genome-editing strategy to treat $\beta$-hemoglobinopathies that recapitulates a mutation associated with a benign genetic condition. Nature Medicine, 22(9), 987-990. doi: 10.1038/nm.4170

- Turton, D. (2004). Lip-plates and 'the people who take photographs': Uneasy encounters between Mursi and tourists in southern Ethiopia. Anthropology Today, 20(3), 3-8. doi: $10.1111 /$ j.0268-540X.2004.00266.x

- US National Library of Medicine. (s. f.). PubMed [Base de datos]. Recuperada de https://www.ncbi.nlm.nih.gov/pubmed/

- Xie, F., Ye, L., Chang, J. C., Beyer, A. I., Wang, J., Muench, M. O., \& Kan, Y. W. (2014). Seamless gene correction of $\beta$-thalassemia mutations in patient-specific iPSCs using CRISPR/Cas9 and piggyBac. Genome Research, 24(9), 1526-1533. doi: 10.1101/ gr. 173427.114 